\title{
A collagen membrane influences bone turnover marker in vivo after bone augmentation with xenogenic bone
}

Henning Staedt ${ }^{1,2}$, Michael Dau ${ }^{3}$, Eik Schiegnitz ${ }^{4}$, Daniel G. E. Thiem ${ }^{4}$, Olga Tagadiuc ${ }^{5}$, Victor Palarie ${ }^{6}$, Peter Ottl $^{2}$, Bilal Al-Nawas ${ }^{4}$ and Peer W. Kämmerer ${ }^{4^{*}}$

\begin{abstract}
Background: The aim was to compare early biochemical and histological osseous healing of chronic mandibular defects regenerated with bovine bone substitute with and without collagen membrane in vivo.

Methods: Eight weeks after formation of a lateral full-thickness perforating bone defect in the mandible of 40 rabbits, bovine bone substitute with ("+ $+; n=20)$ and without (" $-" ; n=20)$ collagen membrane was applied. Blood and bone was collected 24, 72 h, 7, 14 and 21 days after surgery. Total acid phosphatase, bone acid phosphatase, total alkaline phosphatase and bone alkaline phosphatase activities were compared between groups. Formation of new bone was quantified histologically for all time points.
\end{abstract}

Results: Twenty-four hours after surgery, bone alkaline phosphatase was significantly elevated in " + " group when compared to "-" ( $p=0.012)$. After 72 hours, all bone turnover markers except for total acid phosphatase $(p=0.078)$ where significantly elevated in " + " (all $p<0.05$ ). Fourteen days after surgery, the significant highest values for all bone turnover markers were detected in "-" (all $p<0.05$ ). A significant difference in favor of group "-" could also be detected after 3 weeks in terms of both acid phosphatases $(p<0.05)$. In histology, no significant differences could be detected.

Conclusion: Bone regeneration with bovine bone substitute material and collagen membrane shows a significantly earlier bone remodeling activity but does not seem to influence formation of new bone in histological samples.

Keywords: Bone regeneration, Membrane, Collagen, Bone remodeling, Serological bone turnover markers, Animal study

\section{Background}

Guided bone regeneration (GBR) is an established treatment method for regeneration of osseous defects of the jaws. GBR is based on a bone graft material and a barrier membrane to cover and stabilize the augmented bone defect [1-3]. Membranes for GBR can be divided into nonresorbable and resorbable. Non-resorbable systems include

\footnotetext{
* Correspondence: peer.kaemmerer@unimedizin-mainz.de; peer.kaemmerer@gmx.de

${ }^{4}$ Department of Oral, Maxillofacial Plastic Surgery, University Medical Center Mainz, Augustusplatz 2, 55131 Mainz, Germany

Full list of author information is available at the end of the article
}

titanium meshes and polytetrafluoroethylene membranes. Those materials have to be removed in a second procedure after completion of the regenerative bone healing [4], whereas absorbable membranes are dissolved by catalytic processes $[2,5]$. These membranes mostly consist of porcine or bovine collagen and are characterized by a good barrier function $[3,6]$. As a biomaterial, collagen has a number of properties including low immunogenicity, fast vascularization, promotion of wound healing and even bone regeneration [7-11]. It was shown that the material allows sufficient diffusion of nutrients for cellular proliferation and differentiation [12]. Deproteinized bovine bone is a well-

(c) The Author(s). 2020 Open Access This article is licensed under a Creative Commons Attribution 4.0 International License, which permits use, sharing, adaptation, distribution and reproduction in any medium or format, as long as you give appropriate credit to the original author(s) and the source, provide a link to the Creative Commons licence, and indicate if changes were made. The images or other third party material in this article are included in the article's Creative Commons licence, unless indicated otherwise in a credit line to the material. If material is not included in the article's Creative Commons licence and your intended use is not permitted by statutory regulation or exceeds the permitted use, you will need to obtain permission directly from the copyright holder. To view a copy of this licence, visit http://creativecommons.org/licenses/by/4.0/ The Creative Commons Public Domain Dedication waiver (http://creativecommons.org/publicdomain/zero/1.0/) applies to the data made available in this article, unless otherwise stated in a credit line to the data. 
documented natural hydroxyapatite that promotes bone healing and implant osseointegration during osseous regeneration procedures in the jaws [3, 13-17]. Besides, it has shown to be resistant to resorption [18]. The combination of resorbable collagen membranes with underlying bovine bone substitute material successfully led to osseous regeneration in animal models as well as in human jaws [3, 19-21].

Radiological examination is the standard method for estimating the osseous healing and consolidation process after augmentation. However, correlations between healing status and callus resistance are assumed to be very low [22]. Bone turnover markers are products of bone cell activity, have a prognostic value for early detection of osseous healing $[22,23]$ and might be an interesting alternative for evaluation of graft remodeling. Bone turnover markers can be divided into bone resorption and formation markers. Tartrate-resistant acid phosphatase is mainly present in osteoclasts and - to a lesser extent - in osteoblasts and osteocytes [24-27]. Alkaline phosphatase is attached to the outer surface of cells and matrix vesicles and has an important role in development and mineralization of bone. In brief, acid phosphatase may facilitate bone mineralization in the osteocyte lacunae and alkalic phosphatase positively influences osteoblast-derived mineralization. Both bone remodeling enzymes exhibit significant activity versus the mineralization inhibitor inorganic pyrophosphate and regulate osteopontin, that could inhibit de novo bone formation $[24,28]$. However, there are no studies examining activity of bone turnover markers after bone augmentation procedures in the jaws so far.

Therefore, this experimental project was designed to evaluate differences in the sequential osseous healing events that occur during early stages of bone regeneration in mandibular chronic lateral ridge defects in rabbits using bovine bone substitute material covered or non-covered with a collagen membrane. The outcomes of bone regeneration were measured by the activities of acid phosphatase and alkaline phosphatase in peripheral blood and within bone as well as by histological measurement of new formed bone within the augmented defect.

\section{Methods}

\section{Study materials}

Deproteinized bovine bone substitute material (BBSM; BioOss; Geistlich Pharma AG, Wolhusen, Switzerland; granularity $1-2 \mathrm{~mm}$ ), as well as resorbable, non-cross-linked collagen membranes (Bio-Gide; Geistlich Pharma AG, Wolhusen, Switzerland) were used. BBSM is deproteinized bovine cancellous bone with a structure similar to human bone and osteoconductive characteristics. In brief, it consists of a natural, non-antigenic, porous bone mineral matrix and it is produced by removal of all organic components from bovine bone $[3,29]$. The porcine-derived type I and III collagen membrane has a bilayer structure, consisting of a compact outer layer and a porous inner layer of collagen fiber bundles [10]. Both materials, alone and in combination by means of GBR-procedures, are frequently used in preclinical as well as clinical regenerative maxillofacial surgery [3, 18, 30-32].

\section{Experimental animal model}

The study was planned prospectively in accordance to the ARRIVE guidelines [33] and the EU Directive 2010/63/EU for animal experiments. The animal experiments were approved by the Research Ethics Committee for Laboratory Animals at the University of Medicine and Pharmacy "Nicolae Testemitanu", Chisinau, Moldova. Fourty, 9 months old, $4-5 \mathrm{~kg}$, female New Zealand white rabbits were used for the in vivo experiments. All animals were treated in accordance with both policies and principles of laboratory animal care and with the European Union guidelines. The rabbits were housed in individual cages in an animal room maintained at $22^{\circ} \mathrm{C}$ and $55 \%$ relative humidity with ventilation $18-20$ times/h and a 12-h lightdark cycle. They were allowed free access to diet and water. The treatment consisted of two surgical approaches under general anesthesia (intramuscular injections of a combination of a dose of $35 \mathrm{mg} / \mathrm{kg}$ body weight ketamine and a dose of $5 \mathrm{mg} / \mathrm{kg}$ body weight xylazine) each. Prior to any surgical intervention, local anesthetic was applied (4\% articaine with 1:200.000 epinephrine (Ultracaine DS, Sanofi, Frankfurt am Main, Germany)) followed by disinfection using chlorhexidine (Chlorhexamed FORTE 0.2\%, GlaxoSmithKline Consumer Healthcare, Bühl, Germany). At the first surgical step, a full thickness critical size perforating bone defect removing both cortical plates and the trabecular bone [34] $(1 \times 1 \mathrm{~cm})$ was created at the right side of the mandible in all animals after incision of the skin and elevation of the periosteum. The wounds were closed with absorbable sutures (Vicryl 4-0 (Ethicon $\mathrm{GmbH}$, Norderstedt, Germany)). Eight weeks after formation of the defect, the regeneration procedure was carried out. In brief, using the same surgical approach as in the first step, the bone was carefully skimmed with a straight fissure carbide bur under copious irrigation with sterile $0.9 \%$ physiological saline to remove remaining soft tissue and to lay open fresh bone tissue (Fig. 1). In no defect, osseos healing was seen and each defect was augmented using BBSM. In a randomized approach using a computerized list, the animals either received a collagen membrane to cover the BBSM-containing defect (group $+; n=$ 20 ) or none such membrane (group -; $n=20$ ). The membranes were put under the periosteum and no further fixation was conducted. The mucoperiosteal flaps, muscles, subcutaneous tissue and skin were advanced, repositioned anatomically and fixed via interrupted and mattress sutures with Vicryl 4-0. Postoperatively, Ibuprofen (2-10 $\mathrm{mg} / \mathrm{kg}$ body weight orally) was used for analgesia. 


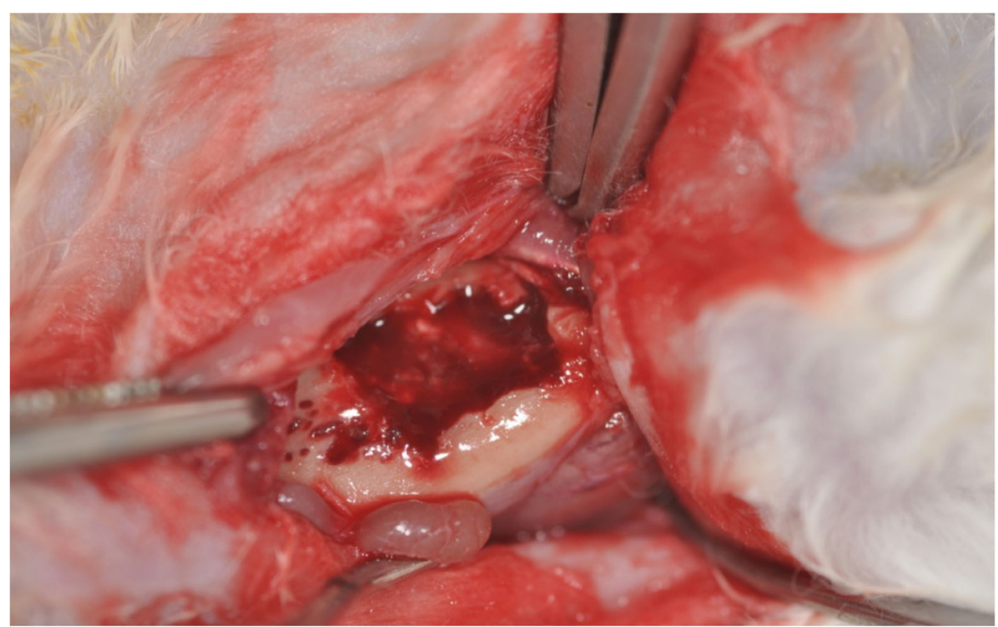

Fig. 1 Bone defect in the rabbit mandible before bone grafting procedure

\section{Measurements}

\section{Bone turnover marker}

The outcomes of bone regeneration were measured by activities of total acid phosphatase out of the peripheral blood (TAcPh; Fig. 2), bone acid phosphatase out of the ground bone from the augmented site (BAcPh), total alkaline phosphatase (TAlPh) as well as bone alkaline phosphatase (BAlPh). The peripheral blood (TAcPh; (TAlPh) as well as the bone (BAcPh; BAlPh) samples were collected immediately after 24 and $72 \mathrm{~h}, 7$ days, 2 weeks and 3 weeks after surgery with $n=4$ samples per group. Blood samples were obtained from anesthetized animals before sacrifice. Animals were sacrificed with an intravenous overdose of pentobarbital (100 mg/kg body weight). Half of the augmented sites were removed en bloc, ground into particles and processed for enzyme analysis, using standard kits and following the manufacturer's protocol (Acid Phosphatase Assay Kit CS0740, Sigma-Aldrich, Taufkirchen, Germany; Alkaline Phosphatase Detection Kit AFP, Sigma-Aldrich, Taufkirchen, Germany). The serum was separated by centrifugation at $3000 \mathrm{~g}$ for $10 \mathrm{~min}$ at $37^{\circ} \mathrm{C}$. Aliquots were stored at $80{ }^{\circ} \mathrm{C}$ in appropriate cuvettes.

\section{Histology}

Using the other half of the samples, histological analysis on formation of new bone was carried out. For this purpose, following fixation in $4 \%$ buffered formaldehyde and dehydration, the specimens were embedded in a 1:1 combination of glycol-methacrylate and ultraviolet lightactivated polymethyl-methacrylate (Technovit $7200^{\circ}$ VLC; Heraeus Kulzer, Hanau, Germany) for 5 days. After penetration of the whole specimen by Technovit $7200^{\circ}$ VLC,

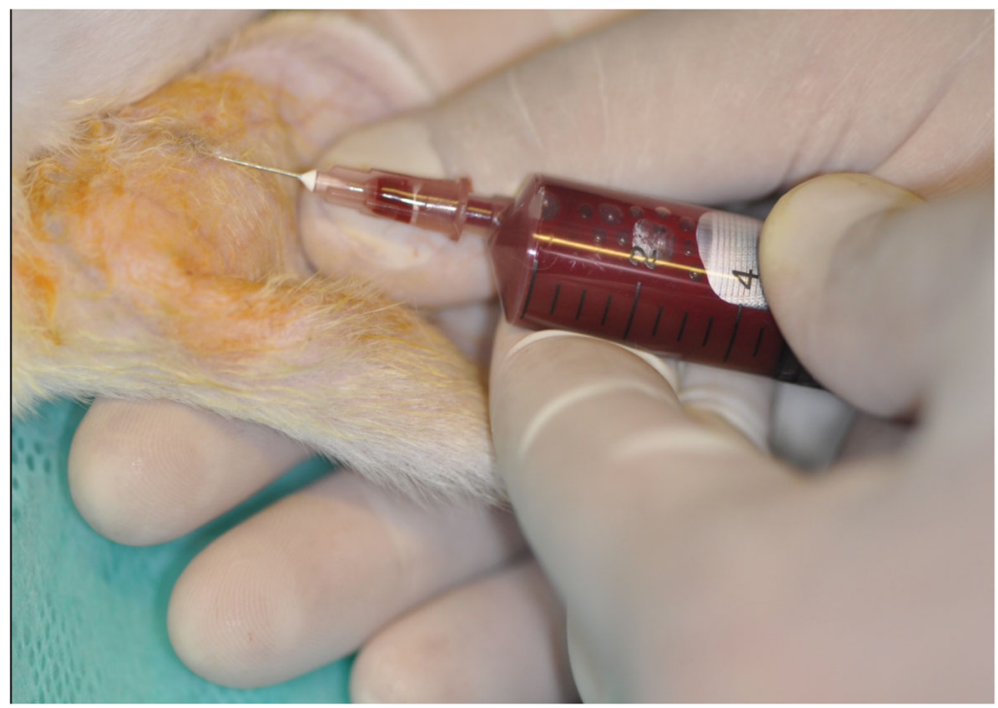

Fig. 2 Collection of peripheral blood from the ear vein of a rabbit 
the slides were carefully photopolymerized and processed applying the sawing and grinding technique [35] by using the microgrinding system EMS (Exact, Norderstedt, Germany) to a thickness of $10-20 \mu \mathrm{m}$ and stained with toluidine blue. Finally, five representative cut and ground sections from the core for each defect were digitized using a color scanner with a resolution of 2400 dpi. Additionally, an empty histology slide with millimeter scale was scanned for calibration. The pictures were digitally edited with imaging software (Adobe Photoshop CS, Adobe Systems Software Ireland Ltd., Dublin, Ireland) in order to amplify the contrast between remaining bone graft material and soft tissue by color-coding. The slides were evaluated histomorphometrically using the computer software Analysis $^{\bullet}$ (Soft-Imaging-Systems, Münster, Germany). For each slide, the amount of new-formed bone within the augmented matrix (\%) was analyzed as described before [16]. For each defect, mean values were created out of 3 slides and used for further calculations. All measurements were therefore performed in triplicates. Examiners were blinded to the kind of augmentation.

\section{Statistics}

The study was carried out as a pilot study as there was no prior analysis on enzymatic activities after guided bone regeneration procedures in the literature. The case number of $n=4$ per time point and group is comparable to other animal studies reporting GBR-procedures [3, 36, 37]. Comparisons were conducted between the membrane groups and between the different time periods for each group. A non-parametric Kruskal-Wallis test was used to identify statistical differences between the experimental groups or the time points. Whenever a statistical difference was found, the Mann-Whitney test was applied. Analyses were made using SPSS Version 24 software (SPSS, Inc., Chicago, USA) and the significance level was set at $p<0.05$. The data are presented as the mean \pm standard deviation. $P$-values $<0.05$ were described as "statistically significant", although no adjustment for multiple tests has been applied and the $p$ values are reported descriptively only.

\section{Results}

The post-operative healing was generally uneventful. All animals completed the study and could be included in the descriptive statistical analysis. No complications such as fractures, allergic reactions, swellings, abscesses, or infections were noticed throughout the entire study period.

\section{Bone turnover marker}

Twenty-four hours after surgery, bone alkaline phosphatase $(\mathrm{BAlPh})$ was significantly elevated in the collagen $(+)$ group when compared to the non-collagen samples $(p=0.012$; Table 1). After $72 \mathrm{~h}$, all bone turnover markers except for TAcPh $(p=0.078)$ where significantly elevated in the group treated with collagen membranes (BAcPh: $p=0.005$, TAlPh: $p=0.013$, BAlPh: $p=0.06$; Table 1, Fig. 3). Seven days after surgery, none such differences were seen anymore (Table 2). Fourteen days after surgery, the significant highest values for all bone turnover markers were detected in the group without collagen membrane (TAcPh: $p=$ 0.016, BAcPh: $p=0.031$, TAlPh: $p=0.038$, BAlPh: $p=$ 0.036; Table 2, Fig. 4). A significant difference in favor of group "-" could also be detected after 3 weeks in terms of acid phosphatase (TAcPh: $p=0.01, \mathrm{BAcPH}$ : $p=0.026$; Table 2).

\section{Histology}

At $24 \mathrm{~h}, 72 \mathrm{~h}$ and 7 days (Fig. 5) after surgery, no new bone formation was seen in both groups. After 14 days, a decent osseous growth coming from the residual bone could be detected, that did not show any significant difference between groups (group "+": 5.5\% (standard deviation: $4.2 \%$ ), group "-": $3.3 \%$ (standard deviation: $3.1 \%$ ); $p=0.12$; Fig. 6). After 3 weeks, there was no significant difference between groups as well (group "+": 54.4\% (standard deviation: 7.7\%), group “-": 49.3\% (standard deviation: $5.9 \%) ; p=0.25$ ).

\section{Discussion}

To the best of our knowledge, this is the first study that investigated the enzymatic activity in blood and bone after augmentation of bone defects with a bovine bone substitute material, covered or not covered with a collagen membrane. In the early healing phase $24 \mathrm{~h}$ after

Table 1 Mean values as well as standard deviations for all bone turnover markers at $24 \mathrm{~h}$ and $72 \mathrm{~h}$ after augmentation of the defect.

\begin{tabular}{|l|l|l|l|l|}
\hline & $\mathbf{2 4 h}$ & & $\mathbf{7 2 h}$ & \\
\hline & Group Collagen (+) & Group no collagen (-) & + & - \\
\hline Total Acid Phosphatase & $26 \pm 2$ & $23 \pm 1$ & $31.7 \pm 3.5$ & $25.3 \pm 3.1$ \\
\hline Bone Acid Phosphatase & $25.3 \pm 2.1$ & $22.3 \pm 1.5$ & $35.7 \pm 2.1$ & $27.3 \pm 1.5$ \\
\hline Total Alkaline Phosphatase & $242.7 \pm 11.5$ & $224 \pm 17.8$ & $274.9 \pm 4.7$ & $261.7 \pm 2.3$ \\
\hline Bone Alkaline Phosphatase & $186 \pm 6.6$ & $167.7 \pm 3.1$ & $195.3 \pm 3.1$ & $184 \pm 2$ \\
\hline
\end{tabular}




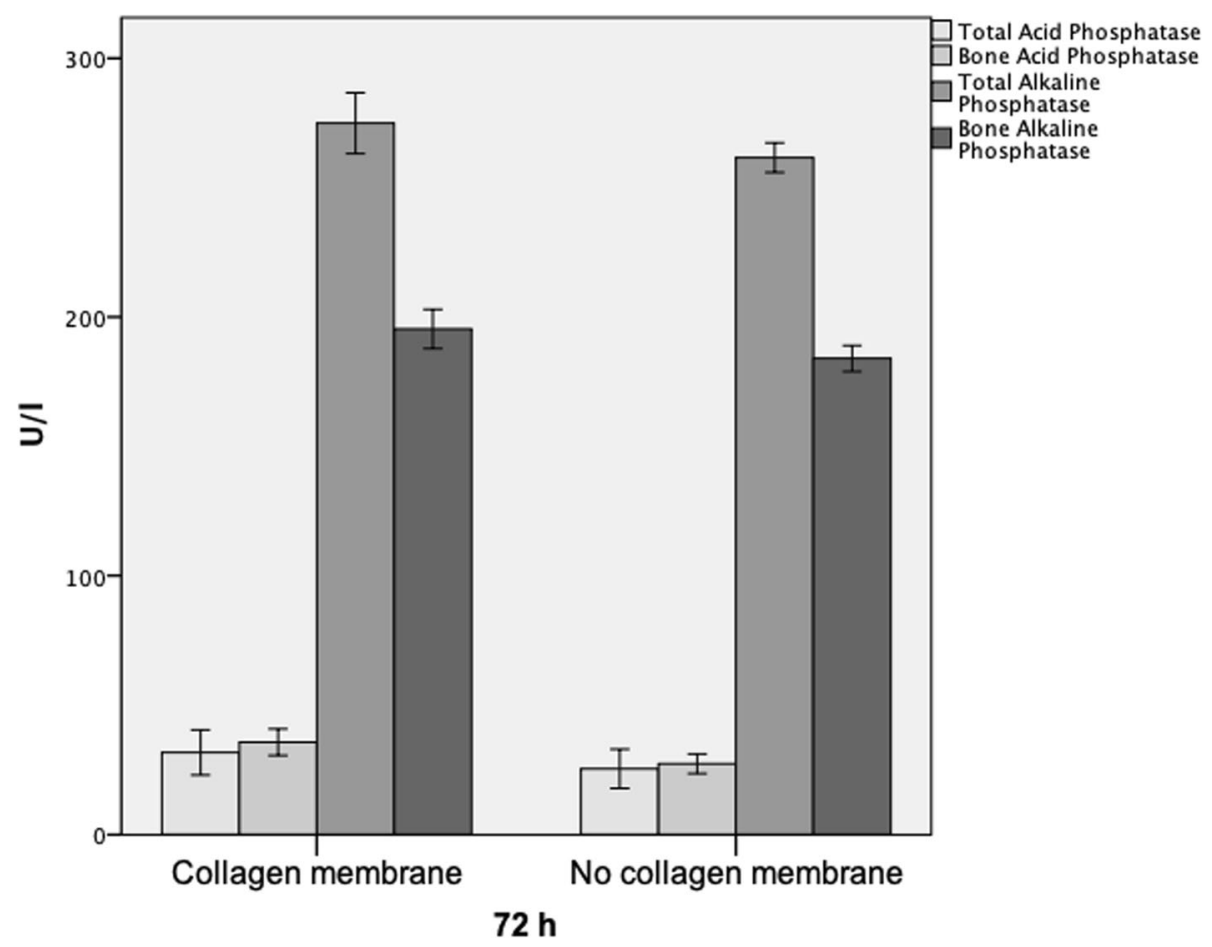

Fig. 3 Bar charts showing expression of all four bone remodeling markers after $72 \mathrm{~h}$. Significant differences in favor of the group with collagen membrane were detected in case of bone acid phosphatase, as well as total and bone alkalic phosphatase (all $p<0.05$ )

surgery, bone alkaline phosphatase (BAlPh) was significantly elevated in the group that received a collagen membrane. After $72 \mathrm{~h}$, the investigated enzymes bone acid phosphatase (BAcPH) as well as total alkaline phosphatase (TAlPh) and BAlPh were significantly higher in the collagen group. In contrast, in the later healing phases - after two and 3 weeks - all enzymes in the group without a membrane showed higher activity. The porcine collagen membrane consists of a thick bilayer structure resulting in a considerable amount of type I and III collagen that might influence early healing activities. In accordance, the modification of the same xenogenic bone substitute with collagen has already shown to increase initial platelet consumption together with a higher release of VEGF, PDGF and TGF-beta when compared to the bone substitute without collagen adjunct [29]. Also, the superiority of allogenic bone over xenogenic bone substitutes both in pre- as well as clinical studies has been attributed to its incorporated growth factors and collagen [32, 38, 39].

$\mathrm{TAcPh}$ and $\mathrm{BAcPH}$ are seen as bone resorption marker whereas both TAlPh and BAlPh are assumed to play a role in osteoid formation and bone mineralization [40]. Therefore, the use of a membrane in osseous regeneration procedures of the jaws significantly enhances bone remodeling activity in the early healing phase and accelerates bone regeneration. These results are in accordance to the literature. For example, it could be shown that guided bone regeneration (GBR) procedures result in an increased periimplant bone growth even if a group without membrane was missing in this study [15]. Turri et al. examined the molecular and structural pattern of bone healing in rat

Table 2 Mean values as well as standard deviations for all bone turnover markers $7 \mathrm{~d}, 14 \mathrm{~d}$ and $21 \mathrm{~d}$ after augmentation of the defect.

\begin{tabular}{|l|l|l|l|l|l|l|}
\hline & 7d & & 14d & & 21d & \\
\hline & Group Collagen (+) & Group no collagen (-) & + & - & + & - \\
\hline Total Acid Phosphatase & $17.3 \pm 3.2$ & $16 \pm 2$ & $16.3 \pm 2.1$ & $22.3 \pm 1.5$ & $14.3 \pm 3.5$ & $24.2 \pm 1.1$ \\
\hline Bone Acid Phosphatase & $14.7 \pm 2.5$ & $13.3 \pm 2.1$ & $12.7 \pm 1.5$ & $16.2 \pm 1$ & $12.6 \pm 2.8$ & $18.7 \pm 1.4$ \\
\hline Total Alkaline Phosphatase & $175 \pm 63.2$ & $215.8 \pm 5$ & $217.3 \pm 4.7$ & $227.7 \pm 3.5$ & $173 \pm 8.7$ & $179 \pm 12.5$ \\
\hline Bone Alkaline Phosphatase & $179.9 \pm 4.4$ & $180.3 \pm 3.7$ & $147.7 \pm 6.5$ & $161 \pm 3.6$ & $145 \pm 4.8$ & $143.6 \pm 3.8$ \\
\hline
\end{tabular}




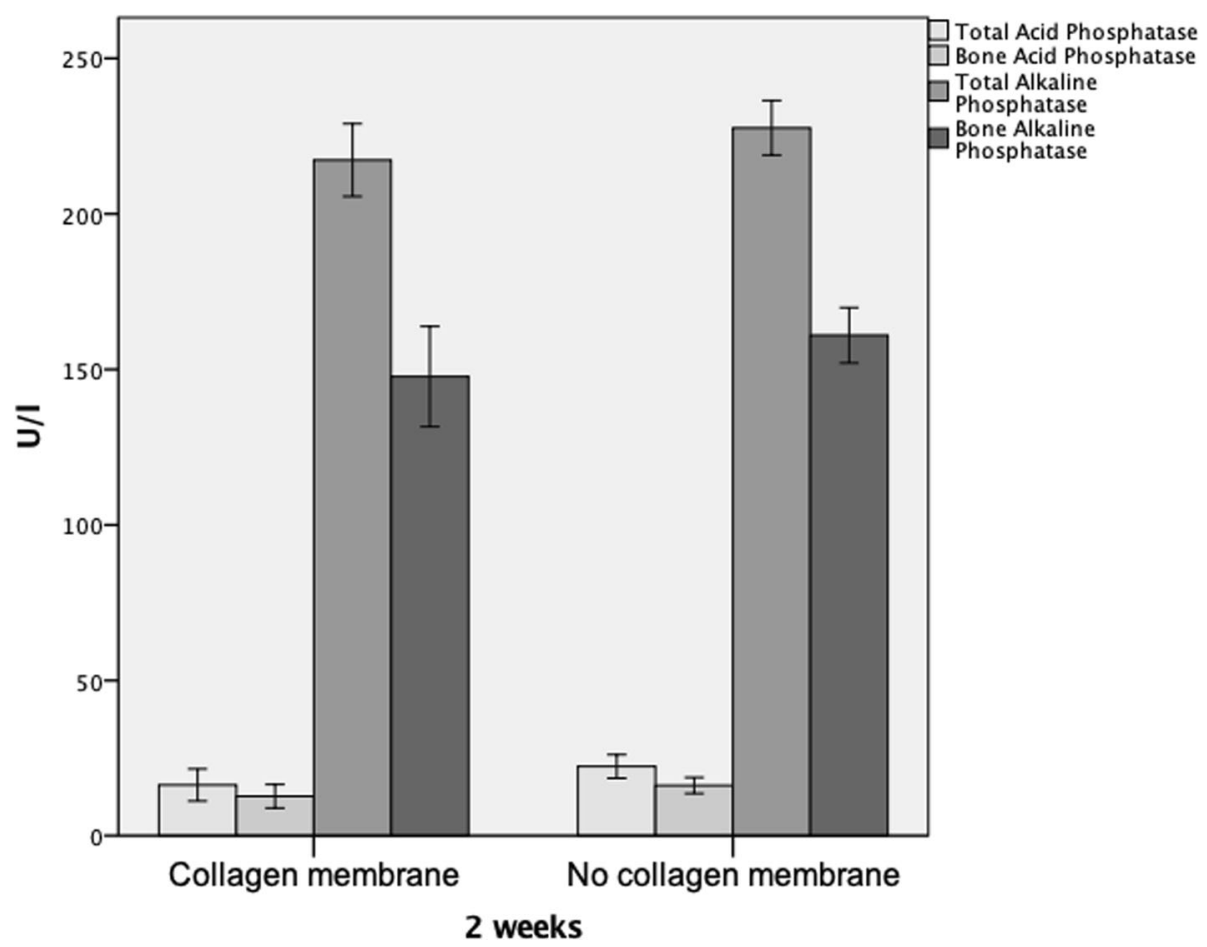

Fig. 4 Bar charts showing expression of all four bone remodeling markers after 2 weeks. Significant differences in favor of the non-collagen group were detected in case of all four bone remodeling markers (all $p<0.05$ )

femurs bone defects with and without naturally derived resorbable membranes. In this study, in contrast to our study, histomorphometry showed that the presence of the membrane promoted bone formation in early and late periods. In concordance, upregulation of cell recruitment and coupled bone remodeling genes in the defect were seen. Cells recruited into the membrane expressed signals for bone regeneration like BMP-2, FGF-2, TGF-b1 and VEGF. Western blot and immunohistochemistry analysis demonstrated that the single native membrane contained FGF-2 but not BMP-2. However, an accumulation of FGF-2 and BMP-2 proteins and immunoreactive cells were demonstrated in the implanted membrane in vivo. Though, the authors used a rat femur model without bone substitute materials. In the present study, a full thickness critical size, perforating bone defect [34] reconstructed with a xenogenic bone substitute material was assessed; therefore, the results of Turri et al. cannot be extrapolated to the present study [2]. Several studies have shown that serum and urinary bone turnover markers are able to reflect the healing process depending on the location, type and size of the defect [41]. In an animal study by Komnenou et al., as well as in a study by Singh Ajai et al. in human patients, alkaline phosphatase (AlPh) activity was determined throughout the healing process of fractures. In the group of patients who had a normal bone healing compared to the delayed healing group, significantly higher serum AlPh activity levels were found. The serum levels of AlPh are the sum of the iso-enzymes from the intestine, placenta, liver and bone. The bone AlPh and liver isoforms represent the most relevant fraction of total $\mathrm{AlPh}$ activity, with an almost equal contribution to about $95 \%$ of this enzyme. In the absence of pregnancy and liver or intestinal disorders, AlPh activity could be a low-cost marker for monitoring the bone fracture healing process [41-43]. Plagnat et al. even suggested that longitudinal monitoring of AlPh in peri-implant crevicular fluid has a potential to be a marker for dental implant failure [44]. In consideration of the change over time of the mean values of the AlPh-level, the AlPh-level decreased in the test group after 1-4 weeks and then increased after 6, 8, 10 and 12 weeks. These results are similar to those of an animal study on gene expression of AlPh during the osseointegration period [45]. However, Tirachaimongkol and colleagues noted no significant differences in AlPh levels over time [46]. Piattelli and colleagues analyzed the histochemical characterization of AlPh and acid phosphatase $(\mathrm{AcPh})$ at the bone-implant interface after the insertion of smooth screw-shaped threaded titanium implants in rabbit tibia [47]. It was found that there is a strong decrease in AlPh activity from the third week. After 2 months it could be noticed that the AlPh and AcPh activities were similar, possibly in terms of bone remodeling.

In the present study, both BAlPh and TAlPh reached their peak after $72 \mathrm{~h}$ and rose again between the first 


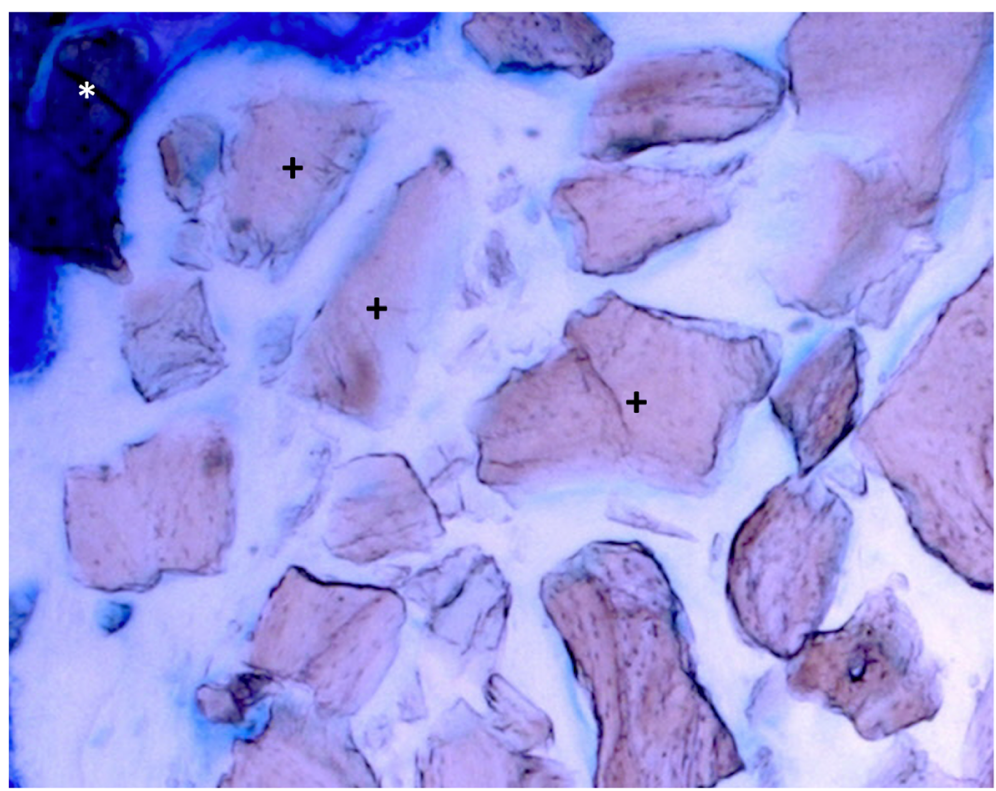

Fig. 5 Histology (toluidine blue, original magnification $\times 20$ ) of a specimen (group with collagen membrane) after 7 days. No new bone formation can be seen. ${ }^{*}=$ residual bone at the edge of the defect; $+=$ bovine bone substitute particles

and second postoperative week, both in the membrane group and in the non-membrane group. This has been demonstrated in earlier studies as well [23, 48-51]. As for the bone specific isoform BAlPh, Emami et al. demonstrated lower values in patients with delayed healing earlier in the fracture healing process than patients with normal bone union [48].

Though, even if significant differences in bone turnover marker between the groups with and without collagen membrane were seen in our study, this did not seem to influence the formation of new bone in toluidine blue stained histological sections. Lateral wall defects with three to four intact bone walls have a comparable high biological capacity for regeneration [52]. For those defects in the jaws - if the bone substitute material can be stabilized properly - the clinical advantageous effect of barrier membranes could not be proven yet $[17,53]$. On contrary, more demanding defects have shown to benefit from GBR-techniques [54], maybe also because of the early increase platelet-derived growth factors [29] in combination

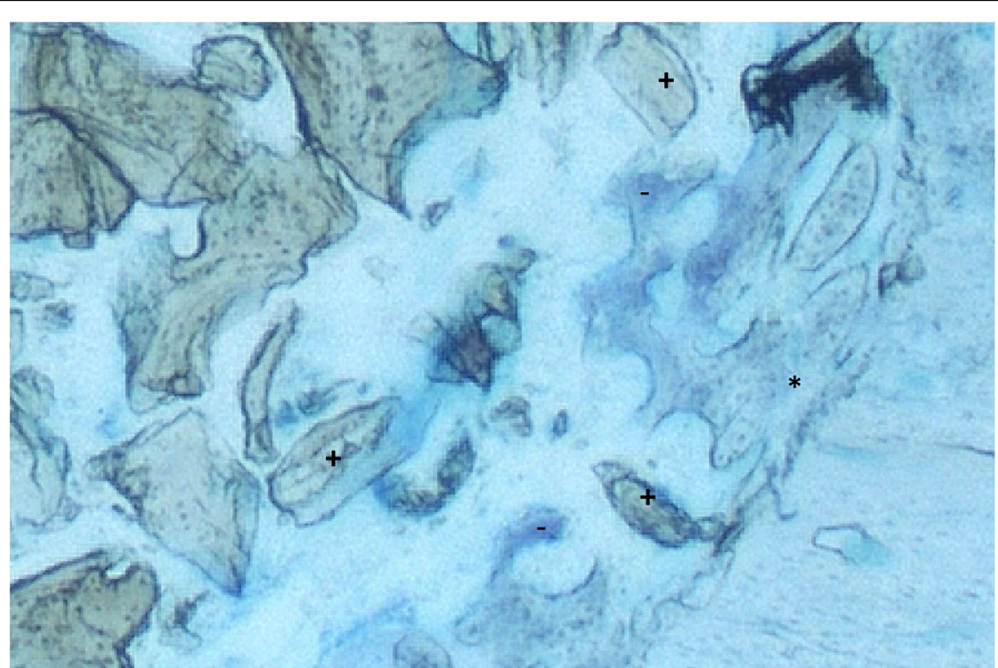

Fig. 6 Histology (toluidine blue, original magnification $\times 20$ ) of a specimen (group with collagen membrane) after 14 days. New osseous growth coming from the residual bone onto the grafted material can be seen. ${ }^{*}=$ residual bone at the edge of the defect; $+=$ bovine bone substitute particles; - = new-formed bone growing from the residual bone 
with the (later) increase of bone turnover markers as found in the present study. Therefore, a critical size, perforating full thickness defect with limited healing properties [34] was chosen. Even so, for example, at the lingual cortical bone plate, no collagen membrane was applied and therefore no effect can be assumed at this site. In addition, a more elaborated histological analysis including more parameter might be needed that should be focused at in future studies. Also, as there in an increased demand of alloplastic as well as allogeneic materials, these bone substitutes in combination with collagen should be addressed as well.

\section{Conclusion}

Higher levels of enzyme activity indicate a more intense bone remodeling. The results of this study gives hints that GBR with bone substitute particles and collagen membrane show a desirable, significantly earlier bone remodeling activity when compared regeneration procedures with bone substitute particles only. Therefore, the membrane during GBR potentially acts like a bioactive compartment rather than just a passive barrier. Even so, these enzymatic results could not be verified in terms of new bone formation.

\section{Abbreviations}

GBR: GUIDED bone regeneration; BBSM: Bovine bone substitute material; TAcPh: Total acid phosphatase; BAcPh: Bone acid phosphatase; TAlPh: Total alkaline phosphatase; BAIPh: Bone alkaline phosphatase; AlPh: Alkaline phosphatase

\section{Acknowledgements}

Not applicable.

\section{Authors' contributions}

Conceptualization, V.P., H.S. and P.W.K.; Methodology, V.P., H.S., O.T. and P.W.K.; Formal Analysis, H.S., V.P., O.T.; Animal Experiments, V.P., H.S., O.T.; Resources, B.A., P.O., H.S.; Writing - Original Draft Preparation, H.S., M.D., E.S., D.G.E.T., V.P., P.W.K.; Supervision, P.O., B.A., P.W.K.; Project Administration, V.P., D.G.E.T. The author (s) read and approved the final manuscript.

\section{Funding}

No funding was obtained.

\section{Availability of data and materials}

The dataset used and/or analyzed during the current study are available from the corresponding author on reasonable request.

\section{Ethics approval and consent to participate}

The study was planned prospectively in accordance to the ARRIVE guidelines [33] and the EU Directive 2010/63/EU for animal experiments. The animal experiments were approved by the Research Ethics Committee for Laboratory Animals at the University of Medicine and Pharmacy "Nicolae Testemitanu", Chisinau, Moldova.

\section{Consent for publication}

Not applicable.

\section{Competing interests}

The authors declare that they have no competing interests.

\section{Author details}

${ }^{1}$ Private Practice, Esslingen am Neckr, Germany. ${ }^{2}$ Department of Prosthodontics and Materials Science, University Medical Center Rostock,
Strempelstraße 13, 18057 Rostock, Germany. ${ }^{3}$ Department of Oral, Maxillofacial Plastic Surgery, University Medical Center Rostock, Schillingallee 35, 18057 Rostock, Germany. ${ }^{4}$ Department of Oral, Maxillofacial Plastic Surgery, University Medical Center Mainz, Augustusplatz 2, 55131 Mainz, Germany. ${ }^{5}$ Laboratory of Biochemistry, State University of Medicine and Pharmacy "Nicolae Testemitanu", Stefan cel Mare si Sfant Boulevard 165, 2004 Chisinau, Moldova. 'Laboratory of Tissue Engineering and Cell Cultures, State University of Medicine and Pharmacy "Nicolae Testemitanu", Stefan cel Mare si Sfant Boulevard 165, 2004 Chisinau, Moldova.

Received: 29 July 2020 Accepted: 24 November 2020

Published online: 07 December 2020

\section{References}

1. Retzepi M, Donos N. Guided bone regeneration: biological principle and therapeutic applications. Clin Oral Implants Res. 2010;21(6):567-76.

2. Turri A, Elgali I, Vazirisani F, Johansson A, Emanuelsson L, Dahlin C, et al. Guided bone regeneration is promoted by the molecular events in the membrane compartment. Biomaterials. 2016;84:167-83.

3. Kämmerer PW, Palarie V, Schiegnitz E, Nacu V, Draenert FG, Al-Nawas B. Influence of a collagen membrane and recombinant platelet-derived growth factor on vertical bone augmentation in implant-fixed deproteinized bovine bone--animal pilot study. Clin Oral Implants Res. 2013;24(11):1222-30.

4. Hartmann $\mathrm{A}$, Hildebrandt $\mathrm{H}$, Schmohl JU, Kämmerer PW. Evaluation of risk parameters in bone regeneration using a customized titanium mesh: results of a clinical study. Implant Dent. 2019;28(6):543-50.

5. Machtei EE. The effect of membrane exposure on the outcome of regenerative procedures in humans: a meta-analysis. J Periodontol. 2001;72(4):512-6.

6. von Arx T, Broggini N, Jensen SS, Bornstein MM, Schenk RK, Buser D. Membrane durability and tissue response of different bioresorbable barrier membranes: a histologic study in the rabbit calvarium. Int J Oral Maxillofac Implants. 2005;20(6):843-53.

7. Wang HL, Carroll MJ. Guided bone regeneration using bone grafts and collagen membranes. Quintessence Int. 2001;32(7):504-15.

8. Bunyaratavej P, Wang HL. Collagen membranes: a review. J Periodontol. 2001; $72(2): 215-29$

9. Parrish LC, Miyamoto T, Fong N, Mattson JS, Cerutis DR. Non-bioabsorbable vs. bioabsorbable membrane: assessment of their clinical efficacy in guided tissue regeneration technique. A systematic review. J Oral Sci. 2009;51(3):383-400.

10. Dau M, Volprich L, Grambow E, Vollmar B, Frerich B, Al-Nawas B, et al. Collagen membranes of dermal and pericardial origin - in vivo evolvement of vascularization over time. J Biomed Mater Res A. 2020;108(12):2368-78.

11. Blatt S, Burkhardt V, Kämmerer PW, Pabst AM, Sagheb K, Heller M, et al. Biofunctionalization of porcine-derived collagen matrices with platelet rich fibrin: influence on angiogenesis in vitro and in vivo. Clin Oral Investig. 2020; 24(10):3425-36.

12. Schwarz F, Rothamel D, Herten M, Sager M, Becker J. Angiogenesis pattern of native and cross-linked collagen membranes: an immunohistochemical study in the rat. Clin Oral Implants Res. 2006;17(4):403-9.

13. Fontana F, Santoro F, Maiorana C, lezzi G, Piattelli A, Simion M. Clinical and histologic evaluation of allogeneic bone matrix versus autogenous bone chips associated with titanium-reinforced e-PTFE membrane for vertical ridge augmentation: a prospective pilot study. Int J Oral Maxillofac Implants. 2008;23(6):1003-12.

14. Maiorana C, Sigurta D, Mirandola A, Garlini G, Santoro F. Sinus elevation with alloplasts or xenogenic materials and implants: an up-to-4-year clinical and radiologic follow-up. Int J Oral Maxillofac Implants. 2006;21 (3):426-32.

15. Kämmerer PW, Scholz M, Baudisch M, Liese J, Wegner K, Frerich B, et al. Guided bone regeneration using collagen scaffolds, growth factors, and periodontal ligament stem cells for treatment of Peri-implant bone defects in vivo. Stem Cells Int. 2017;2017:3548435.

16. Dau M, Kämmerer PW, Henkel KO, Gerber T, Frerich B, Gundlach KK. Bone formation in mono cortical mandibular critical size defects after augmentation with two synthetic nanostructured and one xenogenous hydroxyapatite bone substitute - in vivo animal study. Clin Oral Implants Res. 2016;27(5):597-603.

17. Pabst A, Kämmerer PW. Collagen matrices: opportunities and perspectives in oral hard and soft tissue regeneration. Quintessence Int. 2020;51(4):318-27.

18. Klein MO, Kämmerer PW, Götz H, Duschner H, Wagner W. Long-term bony integration and resorption kinetics of a xenogeneic bone substitute after sinus floor augmentation: histomorphometric analyses of human biopsy specimens. Int J Periodontics Restorative Dent. 2013;33(4):e101-10. 
19. Hammerle $\mathrm{CH}$, Lang NP. Single stage surgery combining transmucosal implant placement with guided bone regeneration and bioresorbable materials. Clin Oral Implants Res. 2001;12(1):9-18.

20. Zitzmann NU, Scharer P, Marinello CP. Long-term results of implants treated with guided bone regeneration: a 5-year prospective study. Int J Oral Maxillofac Implants. 2001;16(3):355-66.

21. Merli M, Moscatelli M, Mariotti G, Pagliaro U, Raffaelli E, Nieri M. Comparing membranes and bone substitutes in a one-stage procedure for horizontal bone augmentation. Three-year post-loading results of a double-blind randomised controlled trial. Eur J Oral Implantol. 2018; 11(4):441-52.

22. Klein $\mathrm{P}$, Bail HJ, Schell H, Michel R, Amthauer $H$, Bragulla $H$, et al. Are bone turnover markers capable of predicting callus consolidation during bone healing? Calcif Tissue Int. 2004;75(1):40-9.

23. Seebeck P, Bail HJ, Exner C, Schell H, Michel R, Amthauer H, et al. Do serological tissue turnover markers represent callus formation during fracture healing? Bone. 2005;37(5):669-77.

24. Halling Linder C, Ek-Rylander B, Krumpel M, Norgard M, Narisawa S, Millan JL, et al. Bone alkaline phosphatase and tartrate-resistant acid phosphatase: potential co-regulators of bone mineralization. Calcif Tissue Int. 2017;101(1):92-101.

25. Kirstein B, Chambers TJ, Fuller K. Secretion of tartrate-resistant acid phosphatase by osteoclasts correlates with resorptive behavior. J Cell Biochem. 2006;98(5):1085-94.

26. Lau KH, Baylink DJ. Osteoblastic tartrate-resistant acid phosphatase: its potential role in the molecular mechanism of osteogenic action of fluoride. J Bone Miner Res. 2003;18(10):1897-900.

27. Solberg LB, Brorson SH, Stordalen GA, Baekkevold ES, Andersson G, Reinholt FP. Increased tartrate-resistant acid phosphatase expression in osteoblasts and osteocytes in experimental osteoporosis in rats. Calcif Tissue Int. 2014; 94(5):510-21.

28. Millán JL, Whyte MP. Alkaline phosphatase and hypophosphatasia. Calcif Tissue Int. 2016:98:398-416.

29. Kämmerer PW, Schiegnitz E, Alshihri A, Draenert FG, Wagner W. Modification of xenogenic bone substitute materials--effects on the early healing cascade in vitro. Clin Oral Implants Res. 2014;25(7):852-8.

30. Palachur D, Prabhakara Rao KV, Murthy KR, Kishore DT, Reddy MN, Bhupathi A. A comparative evaluation of bovine-derived xenograft (bio-Oss collagen) and type I collagen membrane (bio-Gide) with bovine-derived xenograft (bio-Oss collagen) and fibrin fibronectin sealing system (TISSEEL) in the treatment of intrabony defects: a clinico-radiographic study. J Indian Soc Periodontol. 2014;18(3):336-43.

31. Camelo M, Nevins ML, Lynch SE, Schenk RK, Simion M, Nevins M. Periodontal regeneration with an autogenous bone-bio-Oss composite graft and a bioGide membrane. Int J Periodontics Restorative Dent. 2001;21(2):109-19.

32. Kyyak S, Blatt S, Pabst A, Thiem D, Al-Nawas B, Kämmerer PW. Combination of an allogenic and a xenogenic bone substitute material with injectable plateletrich fibrin - a comparative in vitro study. J Biomater Appl. 2020;35(1):83-96.

33. Kilkenny C, Browne WJ, Cuthill IC, Emerson M, Altman DG. Improving bioscience research reporting: the ARRIVE guidelines for reporting animal research. J Pharmacol Pharmacother. 2010;1(2):94-9.

34. Young $S$, Bashoura AG, Borden T, Baggett LS, Jansen JA, Wong M, et al. Development and characterization of a rabbit alveolar bone nonhealing defect model. J Biomed Mater Res A. 2008:86(1):182-94.

35. Donath K, Breuner G. A method for the study of undecalcified bones and teeth with attached soft tissues. The sage-Schliff (sawing and grinding) technique. J Oral Pathol. 1982;11(4):318-26.

36. He H, Huang J, Ping F, Sun G, Chen G. Calcium alginate film used for guided bone regeneration in mandible defects in a rabbit model. Cranio. 2008;26(1):65-70

37. Chen $T L$, Lu HJ, Liu GQ, Tang DH, Zhang XH, Pan ZL, et al. Effect of autologous platelet-rich plasma in combination with bovine porous bone mineral and bio-guide membrane on bone regeneration in mandible bicortical bony defects. J Craniofac Surg. 2014;25(1):215-23.

38. Bauer TW, Muschler GF. Bone graft materials. An overview of the basic science. Clin Orthop Relat Res. 2000;371:10-27.

39. Moussa NT, Dym H. Maxillofacial bone grafting materials. Dent Clin N Am. 2020;64(2):473-90

40. Albeshri S, Alblaihess A, Niazy AA, Ramalingam S, Sundar C, Alghamdi HS. Biomarkers as independent predictors of bone regeneration around biomaterials: a systematic review of literature. J Contemp Dent Pract. 2018; 19(5):605-18.
41. Sousa CP, Dias IR, Lopez-Pena M, Camassa JA, Lourenco PJ, Judas FM, et al. Bone turnover markers for early detection of fracture healing disturbances: a review of the scientific literature. An Acad Bras Cienc. 2015;87(2):1049-61.

42. Komnenou A, Karayannopoulou M, Polizopoulou ZS, Constantinidis TC, Dessiris A. Correlation of serum alkaline phosphatase activity with the healing process of long bone fractures in dogs. Vet Clin Pathol. 2005;34(1):35-8.

43. Ajai S, Sabir A, Mahdi AA, Srivastava RN. Evaluation of serum alkaline phosphatase as a biomarker of healing process progression of simple diaphyseal fractures in adult patients. Int Res J Biol Sci. 2013;(2):40-3..

44. Plagnat D, Giannopoulou C, Carrel A, Bernard JP, Mombelli A, Belser UC. Elastase, alpha2-macroglobulin and alkaline phosphatase in crevicular fluid from implants with and without periimplantitis. Clin Oral Implants Res. 2002;13(3):227-33.

45. Monjo M, Ramis JM, Ronold HJ, Taxt-Lamolle SF, Ellingsen JE, Lyngstadaas SP. Correlation between molecular signals and bone bonding to titanium implants. Clin Oral Implants Res. 2013;24(9):1035-43.

46. Tirachaimongkol C, Pothacharoen P, Reichart PA, Khongkhunthian P. Relation between the stability of dental implants and two biological markers during the healing period: a prospective clinical study. Int J Implant Dent. 2016;2(1):27.

47. Piattelli A, Scarano A, Piattelli M. Detection of alkaline and acid phosphatases around titanium implants: a light microscopical and histochemical study in rabbits. Biomaterials. 1995;16(17):1333-8.

48. Emami A, Larsson A, Petren-Mallmin M, Larsson S. Serum bone markers after intramedullary fixed tibial fractures. Clin Orthop Relat Res. 1999;368:220-9.

49. Joerring S, Krogsgaard M, Wilbek H, Jensen LT. Collagen turnover after tibial fractures. Arch Orthop Trauma Surg. 1994;113(6):334-6.

50. Kurdy NM. Serology of abnormal fracture healing: the role of PIIINP, PICP, and BSALP. J Orthop Trauma. 2000;14(1):48-53.

51. Lammens J, Liu Z, Aerssens J, Dequeker J, Fabry G. Distraction bone healing versus osteotomy healing: a comparative biochemical analysis. J Bone Miner Res. 1998;13(2):279-86.

52. Terheyden H. Bone augmentation in implantology. Dtsch Zahnarztl Ztg. 2010;6:320-30.

53. Alkanan A, Greenwell H, Patel A, Hill M, Shumway B, Lowy J. Ridge preservation comparing the clinical and histologic healing of membrane vs no-membrane approach to Buccal overlay grafting. Int J Periodontics Restorative Dent. 2019;39(5):643-50.

54. Jepsen S, Schwarz F, Cordaro L, Derks J, Hammerle CHF, Heitz-Mayfield L et al. Regeneration of alveolar ridge defects. Consensus report of group 4 of the 15th European workshop on periodontology on bone regeneration. J Clin Periodontol. 2019;46(Suppl 21):277-86.

\section{Publisher's Note}

Springer Nature remains neutral with regard to jurisdictional claims in published maps and institutional affiliations.
Ready to submit your research? Choose BMC and benefit from:

- fast, convenient online submission

- thorough peer review by experienced researchers in your field

- rapid publication on acceptance

- support for research data, including large and complex data types

- gold Open Access which fosters wider collaboration and increased citations

- maximum visibility for your research: over $100 \mathrm{M}$ website views per year

At BMC, research is always in progress.

Learn more biomedcentral.com/submissions 